\title{
Association of Risk Factors, Frequency and Outcomes of ST-Elevation Segment in MI with Patients' Birth-Month; Data from a Cohort Study in Western Iran
}

\author{
Soraya Siabani ${ }^{1}$, Hossein Siabani², Soosan Mahmoodi ${ }^{3}$ \\ ${ }^{1}$ Department of Health Education and Health Promotion, School of Health \& KCRC Kermanshah University of Medical \\ Sciences (KUMS), Kermanshah, Iran. ${ }^{2}$ Medical School, Department of Anesthesiology \& Cardiovascular Research \\ Center (KCRC), Kermanshah University of Medical Sciences (KUMS), Kermanshah, Iran. ${ }^{3}$ Medical School, \\ Cardiovascular Research Center Kermanshah University of Medical Sciences (KUMS), Kermanshah, Iran.
}

\section{ABSTRACT}

\section{BACKGROUND}

Given newly debates on the association of birth-month with various diseases, we investigated the association of patients' birth-month with a burdensome lethal disease, ST-elevation myocardial infarction (STEMI).

\section{METHODS}

The data comes from an ongoing cohort-registry conducted on patients with STEMI registered to a mega cardiovascular hospital, in Western Iran (2016 - 2019). Baseline and follow-up data were collected using the European observational registry program (EORP) case report form, through interviewing eligible patients and reviewing their medical records. The quality of data as well as ethics considerations has been approved by EORP and Kermanshah University Medical Sciences (KUMS) Ethics Committees.

\section{RESULTS}

Among 2341 patients (81.5 \% male) analysed, the peak of event [myocardial infarction (MI)] was 10 am followed by $8 \mathrm{pm}$. Their mean age $( \pm$ SD) was $60.34 \pm$ 12.40 years, minimum 19 years and maximum 96 years. March was significantly more frequent birth-month $(16.4 \%)(\mathrm{p}<0.001)$. Nevertheless, in terms of MI incidence, no significant variation was found between 12 months of a year, as well as the four seasons. The most common risk factors were smoking, hypertension, hypercholesterolemia and diabetes. About $3.8 \%(n=90)$ died in hospital $(23$ women). More than $6 \%$ of patients expired during the first year of follow up. Although birth- month of $18.89 \%(n=17)$ of those expired was March, the difference was not significant $(p=0.025)$.

\section{CONCLUSIONS}

Among 12 months, March was highly significant common birth-month among patients with STEMI; however, this birth-month was not significantly associated with MI frequency of MI risk factors and/or a worse outcome.

\section{KEY WORDS}

Birth Month, Acute Myocardial Infarction, Heart Attack, Risk Factors, Outcomes.
Corresponding Author:

Dr. Hossein Siabani, Imam Ali Hospital,

Kermanshah Cardiovascular Research Center, Kermanshah University of Medical Sciences, Kermanshah, Iran.

E-mail: h_siabani@yahoo.com

DOI: $10.14260 / j e m d s / 2021 / 799$

How to Cite This Article:

Siabani S, Siabani H, Mahmoodi S. Association of risk factors, frequency and outcomes of ST-elevation segment in MI with patients' birth-month; data from a cohort study in western Iran. J Evolution Med Dent Sci 2021;10(45):3958-3962, DOI: 10.14260/jemds/2021/799

Submission 01-11-2021,

Peer Review 07-12-2021,

Acceptance 13-12-2021,

Published 28-12-2021.

Copyright (c) 2021 Soraya Siabani et al. This is an open access article distributed under Creative Commons Attribution License [Attribution 4.0 International (CC BY 4.0)] 


\section{BACKGROUND}

Myocardial infarction (MI) refers to the presence of evidence of tissue necrosis associated with acute ischemia of the heart. ${ }^{1}$ MI can lead to major complications such as electrical and mechanical disorders of the heart and eventually death. ${ }^{2}$ Cardiovascular diseases (CVDs), myocardial infarction in particular, are the most common cause of death across the world including Iran..$^{3,4}$

During last decades, CVDs have been the leading cause of death in almost all high income countries and majority of middle and low income countries. Even though the percentage of death due to CVD in high income countries recently reduced, in low to middle income countries, unfortunately, there is an increasing trend. According to the World Health Organization (WHO), MI, in addition to mortality, imposes a heavy direct and indirect economic burden on the families and societies. ${ }^{5}$ It is estimated that the incidence of myocardial infarction is 73.3 per 100,000 people in Iran. ${ }^{6}$

To date, various modifiable and non-modifiable risk factors for MI such as age, male sex, family history, hypertension, diabetes mellitus, dyslipidemia/ hypercholesterolemia, and smoking have been introduced.7,8 However, such a multifactorial health issue yet is unknown in many aspects. Scientists keep searching for new information which may bright the dark aspects. Few studies were conducted on past history of patients with MI in which many studies believe that birth time can affect future risk of diseases through modification in the prenatal environment that changes development outlines and progression. Some researchers have gone into patients birthday and before that. ${ }^{9}$

More than 2 millennia ago scientists (e.g. Hippocrates) believed in a strong relationship between health and season in which people born. However, modern medicine was going to miss this for a long time. During last 100 years, just a few researchers examined this hypothesis. ${ }^{10,11}$ And some, on the other hand, were seeking to find cause and effect of the relationships ${ }^{12,13}$ It was surprising when Boland and colleagues in 2015 reported an association between lifetime diseases risk factors and patients' birth-month. ${ }^{14}$ Several studies including a meta-analysis, during the last decade, were seeking for the foot-track of birth-month effecting on various diseases including cardiovascular diseases.15-17 A hospital based study conducted on 12,263 people, in China showed that there was a greater risk of coronary artery diseases for those who were born in November, December, and February in comparison with those born in May. Also, those who were born in December had a higher chance to suffer from heart failure. However, they did not find a significant variety in the incidence of myocardial infarction across birth-months. In that study, researcher, also, searched for association between birth- season and CVDs. They figured out that those who were born in wintertime have more coronary artery disease risks when compared with those who were born in spring. Again, there was not a significant association between coronary artery complications (e.g. MI) and birth-seasons. 16

Still, these studies are too little to come to conclude, especially when we see controversy in the findings. ${ }^{18,19}$ There are controversial ideas about the role of season and month in which people born, in their health and diseases. Therefore, it is the place of conducting new studies in various populations. The current article presents the results of an analysis that has come from a cohort study in Western Iran.

\section{METHODS}

Data analysed in this study, came from an ongoing registry cohort study conducted on patients with ST-segment elevated myocardial infarction who have been registered to the Imam Ali Hospital during 36 months from June 2016 to June 2019. Imam Ali Hospital is a large specialized hospital that serves cardiovascular-related medical services to over two million populations living in Western Iran. The data were collected using a European observational registry program case report form as a standard questionnaire. Baseline data were collected in three steps; patients' arrival, during admission period, and after being discharged from the hospital. Follow up data was collected a year after being discharged from the hospital. The resources of data were patients with STEMI who met the inclusion criteria, through interviewing, plus extracting the results of their pathology tests and imaging results (e.g., ECG, angiography etc.) documented in their medical records. Data included were past medical history, current clinical information and personal characteristics including patients' birth date (from their national ID).

\section{Statistical Analysis}

The quality control of data was approved by EORP (for 18 months they received our data directly). Furthermore, a trained expert medical doctor has reviewed the completed questioners/checklist one by one. Data were analysed using Statistical Package for Social Sciences (SPSS) V22 and applying descriptive and analytical tests (e.g. logistic regression). For example, association between birth-month and the known risk factors (e.g. hypertension, diabetes, high BMI, age, hypercholesterolemia, previous MI, smoking) as well as outcomes (in-hospital death, death after a year, reinfection) were tested using logistic regression.

\section{RESULTS}

Of 2341 patients diagnosed by STEMI, $81.4 \%(\mathrm{n}=1906)$ were male and 435 were female. Among 2341 patients, the peak of event (myocardial infarction) was at 10 am and then at $8 \mathrm{pm}$, and no significant variation of event onset frequency in 12 months or four seasons. Nonetheless, March was most common month birth $(16.4 \%)$ with dramatically different with other months $(\mathrm{p}<0.001)$, followed by September by 11 $\%$ (figure 1 ). The mean age was $60.34 \pm 12.40$ years, minimum 19 years and maximum 96 years. The mean BMI was $26.40 \pm 4.03$ which was significantly more in women $(\mathrm{p}=0.002)$. The most common risk factors were smoking (48.7\%), hypertension (41.5\%), hypercholesterolemia (22 $\%$ ) and diabetes mellitus (20\%). Women had more history of chronic heart failure (5.7 \% vs. $2.5 \%$ in men). 
Only $57 \%$ received primary percutaneous intervention (pPCI). About $3.8 \%(\mathrm{n}=90 / 2341)$ died in hospital before being discharged, 23 death cases were female. Death rate had a significant relationship with the age over 60 years. The mean age of female was 6.6 years more than the male patients. The most important fatal factors for acute myocardial infarction in the elderly were heart failure and female gender. Mortality was significantly higher among female, but using multiple logistic regression, it showed that after adjusting the model for age, there was not a significant mortality difference between two genders.

A year follow-up for 1470 patients enrolled during the first two years was performed successfully. Among them, 164 (11\%) data collected through telephone interview or home visit, and 1304 people came to the hospital to undertake pathology tests, ECG and echocardiography. Ninety one (6.2 $\%)$ patients of 1470 patients who were followed up had died during the first year of follow up. Re-admission rate was $29.77 \%(\mathrm{n}=435), 51$ cases were due to health issues other than CVD problems. About $1.67 \%(n=23)$ of them had at least another heart attack (re-infarction), about $20.5 \%$ suffering from recurrent chest pain and $2.9 \%(\mathrm{n}=42)$ experienced hospitalization. Over $3 \%$ of the patients presented killip class II or more during that period of time. Angiography was performed for $14 \%(\mathrm{n}=191)$, percutaneous coronary intervention (PCI) for $12.6 \%(\mathrm{n}=$ $185)$ and coronary artery bypass grapft (CABG) for $5.7 \%$ $(\mathrm{n}=84)$.

\begin{tabular}{|c|c|c|c|}
\hline Variable & Mean (SD) & Variable & N (\%) \\
\hline Age/y & $60.34 \pm 12.40$ & Female/ Male & 435 (8.5) /1906 (81.5) \\
\hline$\leq 45247(10.6)$ & & History of MI & $\begin{array}{c}269(11.5)+87(3.4) \\
\text { unknown }\end{array}$ \\
\hline $46 \leq 2094(98.4)$ & & $\begin{array}{c}\text { History of } \\
\text { hypertension }\end{array}$ & $\begin{array}{c}972(41.5)+39(1.7) \\
\text { unknown }\end{array}$ \\
\hline $\begin{array}{c}\text { BMI } \leq 24.99912(40.2) \\
25 \leq 1399(58)\end{array}$ & $26.15 \pm 4.00$ & History of angina & $377(16.1)$ \\
\hline $\begin{array}{c}\text { First ejection fraction } \\
\text { (EF) }\end{array}$ & $41.67 \pm 7.65$ & History of $\mathrm{CHF}$ & $\begin{array}{c}74(3.2)+112(4.8) \\
\text { unknown }\end{array}$ \\
\hline Last EF & $39.80 \pm 8.6$ & History of AF & $\begin{array}{c}2(0.1)+144 \\
(6.2) \text { unknown }\end{array}$ \\
\hline Earliest $\mathrm{Hb} \mathrm{mg} / \mathrm{dl}$ & $14.71(1.80)$ & History of stroke & $118(5)$ \\
\hline Lowest $\mathrm{Hb}$ & $13.57 \pm 2.05$ & History of CABG & $72(3.1)$ \\
\hline First PLT 109 cells/l & $\begin{array}{l}242.49 \\
(72.72)\end{array}$ & Previous PCI & $141(4)$ \\
\hline First WBC 109 cells/l & $11.26(5.32)$ & Current smoking & $1141(48.7)$ \\
\hline $\begin{array}{l}\text { LDL cholesterol mg/dl } \\
\qquad(\mathrm{n}=2245)\end{array}$ & $\begin{array}{l}104.66 \\
(32.14)\end{array}$ & History of diabetes & $\begin{array}{l}467(19.9)+43 \\
\text { (1.8)unknown }\end{array}$ \\
\hline HDL cholesterol mg/dl & $41.52(9.71)$ & $\begin{array}{c}\text { History of } \\
\text { hypercholesterolemia }\end{array}$ & $\begin{array}{c}523(22.3)+86(3.7) \\
\text { unknown }\end{array}$ \\
\hline Total cholesterol mg/dl & $\begin{array}{l}177.07 \\
(49.68)\end{array}$ & $\begin{array}{c}\text { Chronic } \\
\text { diseases/surgery }\end{array}$ & $578(24.7)$ \\
\hline Triglyceride $(\mathrm{n}=2093)$ & $\begin{array}{l}145.05 \\
(97.46)\end{array}$ & $\begin{array}{c}\text { Familial } \\
\text { hypercholesterolemia }\end{array}$ & $\begin{array}{c}40(1.7)+39(1.7) \\
\text { unknown }\end{array}$ \\
\hline $\begin{array}{l}\text { Earliest creatinine } \\
\mathrm{mg} / \mathrm{dl}\end{array}$ & $1.20(1.97)$ & History of sleep apnea & $\begin{array}{c}28(1.2)+138(5.9) \\
\text { unknown }\end{array}$ \\
\hline Highest creatinine & $1.32(2.28)$ & Current malignancy & $17(0.7)$ \\
\hline $\begin{array}{c}\text { Systolic blood pressure } \\
\text { at first presentation } \\
\mathrm{mmHg} / \mathrm{ML}\end{array}$ & $\begin{array}{l}134.26 \\
(29.45)\end{array}$ & & \\
\hline $\begin{array}{c}\text { Highest total } \\
\text { cholesterol }(n=2258)\end{array}$ & $\begin{array}{c}177.07 \\
(49.68164)\end{array}$ & \multicolumn{2}{|c|}{ Decided treatment action } \\
\hline First CPK & $\begin{array}{c}1581 \\
(1576.39)\end{array}$ & Angioplasty & $1537(65.5)$ \\
\hline Highest CPK & $\begin{array}{c}1808 \\
(1633.62)\end{array}$ & Thrombolytic therapy & $596(25.5)$ \\
\hline First CK_MB & $30.56(60.66)$ & $\begin{array}{l}\text { Pharmacological } \\
\text { treatment/ } \\
\text { No reperfusion }\end{array}$ & $208(8.8)$ \\
\hline Highest CK_MB & $\begin{array}{l}129.70 \\
(134.2)\end{array}$ & \multicolumn{2}{|c|}{ Therapeutic action performed } \\
\hline First troponin & $0.28(2.06)$ & \multirow{4}{*}{$\begin{array}{c}\text { Angioplasty } \\
\text { Thrombolytic therapy } \\
\begin{array}{c}\text { Pharmacological/ No } \\
\text { reperfusion }\end{array}\end{array}$} & $1337(57)$ \\
\hline Highest troponin & $12.16(69.66)$ & & $596(25.4)$ \\
\hline LDH & $650(773.02)$ & & $408(17.6)$ \\
\hline ESR & $11.46(12.20)$ & & \\
\hline $\begin{array}{l}\text { Heart rate in the } \\
\text { first ECG }\end{array}$ & $78.94 \pm 20.83$ & & \\
\hline Table 1. Th & $\begin{array}{l}\text { Baseline I } \\
\text { in }\end{array}$ & $\begin{array}{l}\text { ata of } 2341 \text { Patients } \\
\text { lestern Iran }\end{array}$ & with STEMI \\
\hline
\end{tabular}

\begin{tabular}{|c|c|c|}
\hline \multirow{2}{*}{$\begin{array}{c}\text { Patients } \\
\text { Birth-Month }\end{array}$} & \multicolumn{2}{|r|}{ Dead/n (\%) } \\
\hline & In-hospital death * & Death during a year after MI** \\
\hline Jan & $6(0.38)$ & $6(5.6)$ \\
\hline Feb & $4(0.25)$ & $9(8.4)$ \\
\hline Mar & $17(1.08)$ & $15(6.7)$ \\
\hline April & $3(0.19)$ & $7(7.2)$ \\
\hline May & $6(0.38)$ & $6(5.6)$ \\
\hline Jun & $3(0.19)$ & $10(8.5)$ \\
\hline Jul & $2(0.16)$ & $5(3.7)$ \\
\hline Aug & $5(0.31)$ & $8(5.7)$ \\
\hline Sep & $6(0.38)$ & $10(5.7)$ \\
\hline Oct & $5(0.31)$ & $5(5.7)$ \\
\hline Nov & $8(0.51)$ & $4(4.9)$ \\
\hline Dec & $7(0.44)$ & $6(5.6)$ \\
\hline Total & $72(4.4)$ & $91(6.2)$ \\
\hline $\begin{array}{l}\text { *Among those } \mathrm{p} \\
\text { first two years }\end{array}$ & $\begin{array}{l}\text { tients registered in the } \\
\text { of the study }(n=1630)\end{array}$ & $\begin{array}{l}\text { ** Among those patients who had } \\
\text { been followed up for one year } \\
(\mathrm{n}=1470)\end{array}$ \\
\hline
\end{tabular}

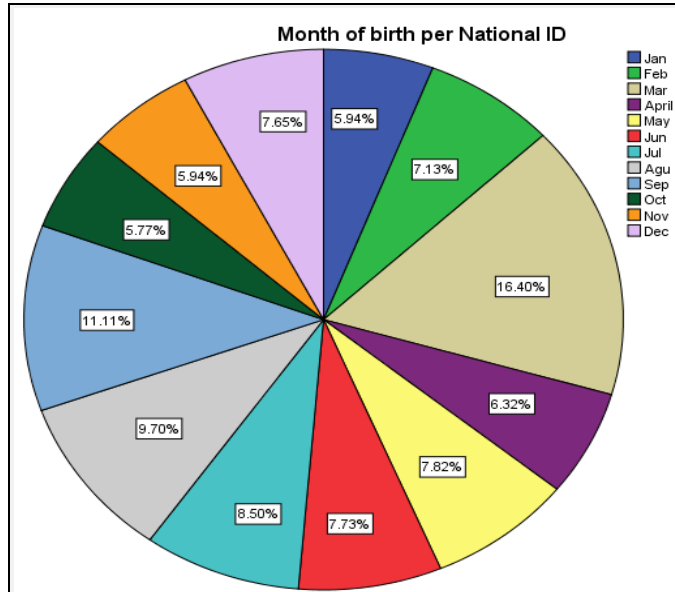

Figure 1. Distribution of 2341 Patients with STEMI per Month They were Born in (the Difference was Significant as Chi-Square Showed a P Value $<0.001$

\section{DISCUSSION}

This study was conducted to investigate the frequency of month patients with STEMI born in, and evaluate the significance of differences as well as association between birth month and risk factors and outcome of the effected patients. The results showed that majority of patients were born in March, and then September. The birth month was highly significant. However, the birth month surprisingly was not significantly associated with the traditional risk factor (e.g., diabetes, hypertension. etc.). Furthermore, we did not find any significant association between short and long outcome and the month of birth.

Researchers analyzed data from more than 115,000 female nurses in the United States between the ages of 30 and 55 who were followed for about 40 years $(1974$ - 2014). During that time, more than 43,000 participants died, of which, 8,360 died of heart disease. The researchers found a link to their month of birth. Women born between March and July are at particular risk of dying from cardiovascular disease, and those born in April are most at risk. Women born in December are at the lowest risk. ${ }^{1}$

In one study, 12,263 BioBank medical records of Xinxiang Medical University affiliated hospital in China were reviewed. 4729 records of patients with coronary artery disease (CAD) (CAD group) and 7534 records of control patients without CAD (control group). 
Birth months were compared between the two groups of patients. Relationships between month of birth and number of CAD and its complications were also examined. They also examined the relationship between birth seasons and the number of CADs and their complications. The results showed that there was a relationship between month of birth and CAD. People born in November, December and February have a higher risk of CAD and people born in winter have a higher risk of CAD. Among CAD patients, those born in January through March and May through September are at higher risk for heart failure. ${ }^{2}$

In a cohort study with 38 years of follow-up in the United States, participants [female nurses $(\mathrm{n}=116911)$ ] were assessed to assess the relationship between birth month, birth season, and cardiovascular mortality (using proportional risk models, Cox). A total of 43,248 people were registered during the 413,6364 years of follow-up since enrollment, including 8,360 deaths from cardiovascular disease. In fully adjusted fully variable analyzes, no significant relationship was observed between month of birth, season of birth and overall mortality. Compared to women born in November, an increase in cardiovascular mortality was observed among those born in March to July (risk ratio for March, 1.09, $95 \%$ confidence interval 0.98 to 1.21; April, 1.12, 1.00 to 1.24; May, $1.08,0.98$ to 1.20 ; June, $1.07,0.96$ to 1.19 ; and July $1.08,0.98$ to 1.20 ). April births had the highest deaths from cardiovascular disease and those born in December had the lowest mortality rates (December, $0.95,0.85$ to 1.06 ). The relative difference between the lowest and highest risk months was $17.89 \%$. Women born in spring $(1.10,1.04$ to 1.17$)$ and summer $(1.09,1.03$ to 1.16$)$ had higher mortality from cardiovascular disease than women born in autumn. Adjustments for family and economic factors did not change these results. The relative difference between the lowest and highest risk of the season was $10.00 \%$. However, no effect of seasonal birth month was observed in women for overall mortality. Family and socio-economic factors do not seem to be able to change these relationships. ${ }^{3}$

The potential impact of birth month on disease risks during life has been studied in a broad-spectrum model of phenomena. This study evaluated the relationships between birth month and 5 cardiovascular outcomes in an independent enrollment of 8,346 patients from Ontario, Canada in 1977 - 2014. The results showed that hypertension and coronary heart disease (primary interest) were more common in those born in January and April, respectively. 4 Despite these new findings, it is still unclear why the month of birth is important. Researchers suspect that this may be due to seasonal changes in a pregnant woman's diet and lack of sunlight before birth. Further studies are needed to confirm these findings and to elucidate the mechanism of these effects of the seasonal birth month on cardiovascular mortality.

Evidence have showed that human reproduction maybe affected by the time of year cycle, and biologic and physiologic reasons have been described somehow. ${ }^{20-}$ ${ }^{22}$ Erhardt et al. after studding 1,387,851 people's birth month during 8 years in the New York City, found that summer is the most frequent season for conception. ${ }^{23}$

Hence, this could be a reason explaining the difference, but is that true in Iran? We searched for Iran birth registries data.

\section{CONCLUSIONS}

On an average, 800 patients with acute STEMI were registered annually in Imam Ali Hospital in Kermanshah. Although we cannot provide an exact prevalence of STEMI in Kermanshah using these data, we can state that over $95 \%$ of the patients with MI, directly or indirectly, attended this hospital because this is the only PCI center in and the main CVD referral hospital in Western Iran. Therefore, the current data would be reliable to judge the related items and STEMI risk factors. A significant percentage of patients had one or more traditional risk factors for heart attack that follow the global pattern. However, the highly prevalent March as the month of birth was a new interesting factor which has been neglected, hence, needs more investigation across the world. If new studies approve our results, it can open a new window to the un-known risk factors or the base of traditional risk factor.

The mean age for female was 7 years more than males. The most important fatal factors for acute myocardial infarction in the elderly were heart failure and female gender. Mortality was significantly higher among female, but using multiple logistic regression showed that after adjusting the model for age, there was not a significant mortality difference between two genders.

Data sharing statement provided by the authors is available with the full text of this article at jemds.com.

Financial or other competing interests: None.

Disclosure forms provided by the authors are available with the full text of this article at jemds.com.

\section{REFERENCES}

[1] Thygesen K, Alpert JS, Jaffe AS, et al. Fourth universal definition of myocardial infarction (2018). Eur Heart J 2019;40(3):237-69.

[2] Saleh M, Ambrose JA. Understanding myocardial infarction. F1000Res 2018;7:F1000 Faculty Rev-378.

[3] Vos T, Lim SS, Abbafati C, et al. Global burden of 369 diseases and injuries in 204 countries and territories, 1990-2019: a systematic analysis for the Global Burden of Disease Study 2019. Lancet 2020;396(10258):120422.

[4] Forouzanfar MH, Sepanlou SG, Shahraz S, et al. Evaluating causes of death and morbidity in Iran, global burden of diseases, injuries, and risk factors study 2010. Arch IranMed 2014;17(5):304-20.

[5] Bloom DEea. The economic burden of chronic diseases: estimates and projections for China, Japan and South Korea. IZA Discussion Papers 2017: p. 10896.

[6] Ahmadi A, Soori H, Mehrabi Y, et al. Incidence of acute myocardial infarction in Islamic Republic of Iran: a study using national registry data in 2012. East Mediterr Health J2015;21(1):5-12.

[7] Ali RA, Asadollah M, Hossien RA. The role of unknown risk factors in myocardial infarction. Cardiol Res 2010;1(1):15-9.

[8] Benjamin EJ, Muntner P, Alonso A, et al. Heart disease and stroke statistics-2019 update: a report from the 
American Heart Association. Circulation 2019;139(10):e56-528.

[9] Colditz GA, Philpott SE, Hankinson SE. The impact of the nurses' health study on population health: prevention, translation, and control. Am J Public Health 2016;106(9):1540-5.

[10] Willer CJ, Dyment DA, Sadovnick AD, et al. Timing of birth and risk of multiple sclerosis: population based study. BMJ 2005;330(7483):120.

[11] Huber S, Fieder M, Wallner B, et al. Brief communication: birth month influences reproductive performance in contemporary women. Hum Reprod2004;19(5):1081-2.

[12] Huber S, Fieder M. Perinatal winter conditions affect later reproductive performance in Romanian women: intra and intergenerational effects. AmJHum Biol 2011;23(4):546-52.

[13] McGrath JJ, Eyles DW, Pedersen CB, et al. Neonatal vitamin D status and risk of schizophrenia: a populationbased case-control study. ArchGen Psychiatry 2010;67(9):889-94.

[14] Boland MR, Shahn Z, Madigan D, et al. Birth month affects lifetime disease risk: a phenome-wide method. J Am Med Inform Assoc 2015;22(5):1042-53.

[15] Boland MR, Fieder M, John LH, et al. Female reproductive performance and maternal birth month: a comprehensive meta-analysis exploring multiple seasonal mechanisms. Scientific Reports 2020;10(1):555.
[16] Zhang BB, Zhao GA, Yang M, et al. Birth month associates with risk of coronary artery disease and its complications: A propensity score matched analysis. Med Clin (Barc) 2019;153(12):454-9.

[17] Poltavskiy E, Spence JD, Kim J, et al. Birth month and cardiovascular disease risk association: is meaningfulness in the eye of the beholder? Online J Public Health Inform 2016;8(2):e186.

[18] Li L, Boland MR, Miotto R, et al. Replicating cardiovascular condition-birth month associations. Scientific Reports 2016;6(1):33166.

[19] Zhang Y, Devore EE, Strohmaier S, et al. Birth month, birth season, and overall and cardiovascular disease mortality in US women: prospective cohort study. BMJ 2019;367:16058.

[20] Cancho-Candela R, Andrés-de Llano JM, ArduraFernández J. Decline and loss of birth seasonality in Spain: analysis of $33,421,731$ births over 60 years. JEpidemiolCommunity Health 2007;61(8):713-8.

[21] Mikulecky M, Lisboa HR. Daily birth numbers in Passo Fundo, South Brazil, 1997-1999: trends and periodicities. BrazJ Med Biol Res2002;35(8):985-90.

[22] Merrow M, Spoelstra K, Roenneberg T. The circadian cycle: daily rhythms from behaviour to genes. EMBO Rep2005;6(10):930-5.

[23] Erhardt CL, Nelson FG, Pakter J. Seasonal patterns of conception in New York City. Am J Public Health 1971;61(11):2246-58. 